\title{
La participación en carreras de fondo como el maratón y la media maratón se asocia a un bajo riesgo de suffir un paro cardiaco o una muerte súbita
}

\section{Participation in long distance races such as the marathon and the half marathon is associated with a low}

risk of heart attack or sudden death

\section{Objetivo}

Evaluar la incidencia, las características y la evolución de los paros cardiacos (PC) que se produjeron en los corredores que participaron en maratones y medias maratones durante el período comprendido entre el 1 de enero del 2000 y el 31 de mayo del 2010 en EE.UU.

\section{Diseño, lugar y pacientes}

La recolección de datos de los corredores fue hecha prospectivamente a través de la base de datos Running USA, que pertenece a una organización no gubernamental dedicada a la organización y control de todas las maratones y medias maratones en la que participan corredores de fondo, en EE.UU.

Para la obtención de los datos de los PC se utilizaron múltiples fuentes de datos (familiares, diarios, sitios web de corredores, búsqueda en Google de palabras claves, registros hospitalarios, etc.). Se analizaron los PC ocurridos durante la carrera y en el área de recuperación posterior a la carrera hasta una hora de finalizada la misma. El análisis de los PC fue hecho retrospectivamente.

\section{Resultados}

La cohorte total de corredores de maratón y media maratón fue de 10,9 millones de participantes. De estos, 59 presentaron un PC, de los cuales 51 a su vez fueron hombres, con una media de edad de $42 \pm 13$ años. Esto da una incidencia de PC de 0,54
Kim J, y col. New Engl J Med 2012;166:130-140. por 100.000 participantes (IC $95 \%$ de 0,41 a 0,70 ). El riesgo fue mayor durante la maratón (1,01 por 100.000 ; IC 95\% de 0,72 a $1,38)$ que durante la media maratón $(0,27$ por 100.000 ; IC $95 \%$ de 0,17 a 0,43$)$. Además el riesgo fue mayor para los hombres $(0,90$ por 100.000 ; IC $95 \% 0,67$ a 1,18$)$ que para las mujeres $(0,16$ por 100.000 ; IC $95 \%$ de 0,07 a 0,31). Dividiendo la muestra temporalmente, el riesgo de PC fue mayor para la segunda mitad de la década estudiada (2005 a 2010: 2,03 por 100.000; IC95\% de 1,33 a 2,98) que para la primera mitad (2000 a 2004: 0,71 por 100.000 ; IC $95 \%$ de 0,31 a 1,40 ).

La causa más prevalente de PC fue la cardiovascular. De los $59 \mathrm{PC}, 42(71 \%)$ fueron fatales con una incidencia de muerte súbita de 0,39 por cada 100.000 (IC $95 \%$ de 0,28 a 0,52) Los predictores de sobrevida más fuertes, en los 32 casos con información completa, fueron el inicio de reanimación cardiopulmonar por un testigo y el de un diagnóstico de causa de PC distinto que miocardiopatía hipertrófica.

\section{Conclusiones}

La participación en carreras de fondo como el maratón y la media maratón se asocia a un bajo riesgo de sufrir un paro cardiaco o una muerte súbita.

Fuente de financiamiento: Revista Runner's World y múltiples fondos de la industria farmacéutica y de la industria de los marcapasos.

\section{Comentario}

Vivimos una paradoja en el deporte y la actividad física: el sedentarismo crece en la población mundial, pero las carreras de calle se multiplican dándonos la falsa percepción de un estilo de vida general más saludable.

Por otro lado, un artículo reciente, que comparó prospectivamente corredores versus no corredores, sugiere una curva riesgo/beneficio de tipo $\mathrm{U}$, donde el menor riesgo cardiovascular se encuentra en aquellos que corren de 1 a 2,4 horas semana'. El beneficio comparado con los no corredores se empieza a perder cuando aumentan las horas de entrenamiento semanal, llegando a equipararse el riesgo cardiovascular entre los no corredores y los corredores que corren más de cuatro horas semanales. Relacionando esta información con los datos del artículo comentado, pareciera ser que los corredores de largas distancias o de volúmenes de entrenamiento semanal alto perderían parte del beneficio cardiovascular de correr. Una potencial fuente de sesgo importante en este estudio es el riesgo de sub registro de eventos (en este caso PC).
Hay que poner en perspectiva la información aportada aquí, dado que esta no es extrapolable a todas las carreras de calle. Aplican para las media maratón y para la maratón. Pero estos corredores son la punta de la pirámide de las carreras, donde la gran base la forman los corredores recreacionales de carreras de $10 \mathrm{~km}$ o menos. El riesgo probablemente sea distinto entre los corredores de distancias menores comparándolos con los atletas entrenados para correr media maratón y maratón que ya pasaron por un filtro de riesgo previo.

Otro dato epidemiológico interesante es que correr es la segunda causa de muerte súbita asociada a deportes en la población general después del ciclismo, según una revisión francesa ${ }^{2}$. Esta asociación puede marcar la popularidad de las carreras de calle como deporte y de su consecuente frecuencia alta de consulta médica por parte de este grupo de deportistas.

Diego Iglesias [ Servicio de Cardiología del Hospital Italiano de Buenos Aires. diego.iglesias@hospitalitaliano.org.ar ]

Iglesias D. La participación en carreras de fondo como el maratón y la media maratón se asocia a un bajo riesgo de sufrir un paro cardiaco o una muerte súbita. Evid Act Pract Ambul. 2015;18(4):121. Oct-Dic. Comentado de: Kim JH, y col. Cardiac Arrest during Long-Distance Running Races. NEJM. 2012;366(2):130-40. PMID: 22236223.

\section{Referencias}

1. Schnohr P, y col. Dose of jogging and long-term mortality. J Am Coll Cardiol. 2015;65:411-9.

2. Marijon E, y col. Sports-related sudden death in the general population. Circulation. 2011;124:672-681. 